\title{
Design and Implementation of Step-Constant Tapered Slot Antennas for UWB Application
}

\author{
Mousumi Aktar'1, Md. Masud Rana1, Md. Sanwar Hossain ${ }^{2}$, Md. Biplob Hossain ${ }^{3 *}$ \\ ${ }^{1}$ Department of Electrica \& Electronic Engineering, Rajshahi University of Engineering \& Technology, Rajshahi, Bangladesh \\ ${ }^{2}$ Department of Electrical and Electronic Engineering, Bangladesh University of Business and Technology, Dhaka, Bangladesh \\ ${ }^{3}$ Department of Electrical and Electronic Engineering, Jashore University of Science and Technology, Jashore, Bangladesh \\ Email: mousumi_05ruet@yahoo.com,md.masud.rana.ruet@gmail.com, sanwareee@gmail.com, ^biplobh.eee10@gmail.com
}

How to cite this paper: Aktar, M., Rana, Md.M., Hossain, Md.S. and Hossain, Md.B. (2019) Design and Implementation of Step-Constant Tapered Slot Antennas for UWB Application. Journal of Sensor Technology, 9, 91-100.

https://doi.org/10.4236/jst.2019.94008

Received: August 26, 2019

Accepted: December 23, 2019

Published: December 26, 2019

Copyright $\odot 2019$ by author(s) and Scientific Research Publishing Inc. This work is licensed under the Creative Commons Attribution International License (CC BY 4.0).

http://creativecommons.org/licenses/by/4.0/

\begin{abstract}
This paper presents the analytical design and high performance of step-constant tapered slot antenna (STSA) for ultra-wideband application. The return loss, radiation pattern, antenna gain, and level of cross polarization of this antenna are presented and analyzed. Utilizing Rogers (RO3006) substrate having a relative permittivity of 6.15 , the proposed antenna provides the ultra-wideband (UWB) from $3.1 \mathrm{GHz}$ to $10.6 \mathrm{GHz}$. It is observed that the return loss and gain are increased with increasing the step size. It has been observed from the simulation results incorporating CST microwave studio commercial software version 2015 , the optimum return loss, directivity and gain are $-43 \mathrm{~dB}, 10.52 \mathrm{dBi}$ and $10.20 \mathrm{~dB}$, respectively, for 15 step size. Therefore, the newly proposed antenna will be a decent candidate for ultra-wideband application.
\end{abstract}

\section{Keywords}

Antenna Gain, Voltage Standing Wave Ratio (VSWR), Step Constant Tapered Slot Antenna (STSA), Ultra Wideband (UWB), Reflection Coefficient

\section{Introduction}

Over the last decade, ultra-wideband (UBW) technology is being used widely due to the diverse applications such as wireless communications [1], remote sensing [2] [3], biosensing [4]-[15], microwave imaging [1], position location [11] [12] [13], tracking [1], and radar system [1]. To transmit a huge amount of digital data, ultra-wideband technology is used which has the ability over wide operating bandwidth with very low power emission for a short distance. The Federal Communications Commission (FCC) of USA provides UWB frequency 
range of $3.1 \mathrm{GHz}$ to $10.6 \mathrm{GHz}$ [16] [17]. The amount of radio frequency (RF) bandwidth $(>500 \mathrm{MHz})$ that is achieved by the UWB system mainly maximizes its performance [16] [17]. However, a quality full communication system depends on antennas that can efficiently radiate and accept UWB signals.

In recent time, various types of antennas have been manifested in the applications of ultra-wideband. Among them tapered slot antenna (TSA) is an important one [18] [19]. A typical tapered slot antenna provides wide operational bandwidth, improves gain, and identical radiation pattern [20]. TSAs can be divided into three basic profiles of taper namely: 1) linear tapered slot antenna (LTSA), 2) constant width slot antenna (CWSA), and 3) exponential tapered slot antenna or Vivaldi antenna [21] [22]. The bandwidth and gain of TSAs are mostly affected by the taper profile.

TSAs are traveling-wave antenna in nature. Generally, by using single or more travelling waves the distribution of voltage or currents of all antennas can be presented which is known as travelling wave antennas. The properties of the traveling wave are, 1) reasonably high directivity 2) thin beam width and 3) nearly identical E-plane and $\mathrm{H}$-plane radiation patterns over a widespread frequency band. Another important benefit of tapered slot antennas is they display broadband action, small side lobes, planar footsteps and simple in construction. If there is a noble match of TSA between the input side and at the radiation side of an antenna, then TSA has a large bandwidth. Greater than $10 \mathrm{GHz}$ operating frequencies TSAs are also suitable, where a large electrical length and a small geometrical length considerably relate to each other. Through conventional geometries the simple direct polarization is the leading drawback of the TSA [23].

In this paper, a micro strip line (L-shape) fed Step-constant tapered slot antenna (STSA) component has been designed by using Rogers (RO3006) substrate. We investigate the use of Rogers (RO3006) substrate based antenna for ultra-wideband applications focusing on multiple key aspects such as 1) reflection coefficient, 2) directivity and antenna gain, 3) voltage standing wave ratio (VSWR) and 4) radiation pattern. In addition, the performance parameters of the designed Rogers-based Step-constant Tapered Slot Antenna have been compared with the conventional UWB antenna for ensuring the validity. However, the key parameters of the antennas are analyzed using a Computer Simulation Technology (CST) microwave studio software version 2015.

\section{Step Constant Tapered Slot Antenna (STSA) Design}

The Tapered slot antenna (TSA) is a traveling wave antenna in which the wave propagates through the tapered slot for radiation. Among the types of TSA, this paper represents the design of the step constant tapered slot antenna (STSA). By the modification of some important parameters most favorable antenna design can be achieved. The basic configuration of the proposed step-constant antenna is shown in Figure 1. The feeding of the antenna is located on the left side of a 
substrate having dielectric constant and thickness of $\varepsilon_{\mathrm{r}}=6.15$ and $h=1.5 \mathrm{~mm}$, respectively. A waveguide port is connected between the micro strip-line to the substrate. At one direction, the width of the strip is $0.4 \mathrm{~mm}$ and the length is 7 $\mathrm{mm}$ long in the creation part. At the other direction, the width of the slot is 0.4 $\mathrm{mm}$ and length is $10 \mathrm{~mm}$, respectively. The final optimized parameters of the antenna are listed in Table 1. In order to construct the step, the following equations are used in where each step has a specific length and width.

Length of the step: $S_{L}=A(L / 2)$

Width of the step: $S_{W}=-A(W / 2), A(W / 2)$

Taper Length: $T_{L}=K^{\star} L / 2$

Taper Width: $T_{W}=K^{\star} W / 2$

where, No. of step $=K(=5,10,15,20,25,30), L=8 \mathrm{~mm}, W=3.9 \mathrm{~mm}$, and $A=$ $1,2,3,4 \ldots$ The back view from Figure 1 (b) shows that, the $L$-shape micro strip-line is used for feeding the step constant tapered slot antenna. The width of the beginning part and the second part is the same but the length is different for better reflection coefficient and gain.

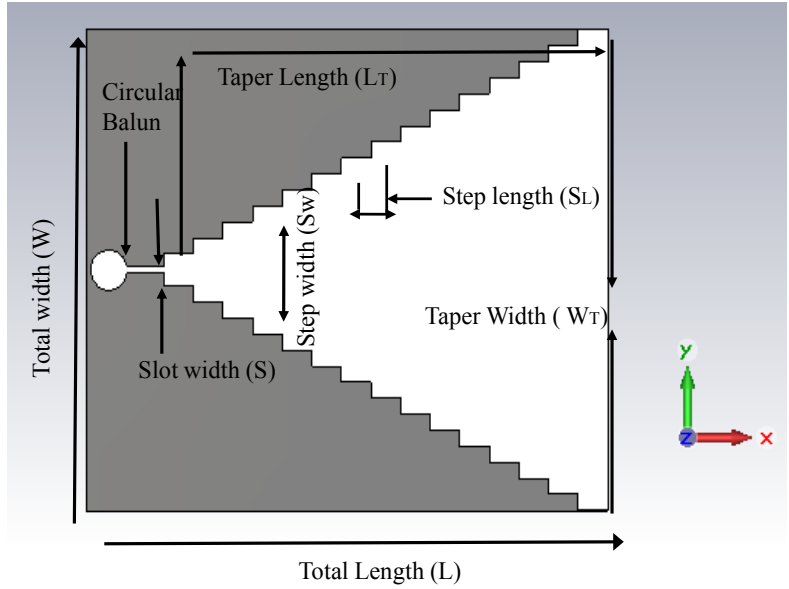

(a) Front view

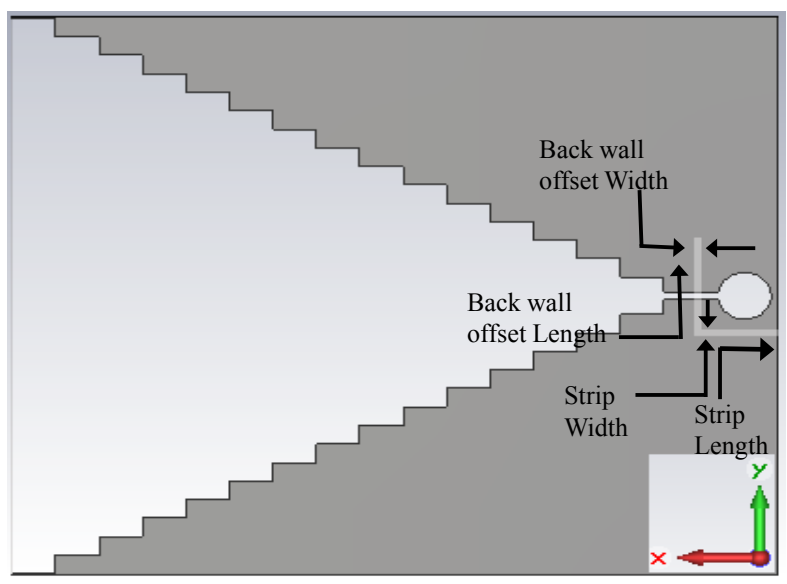

(b) Back view

Figure 1. Structural design of the proposed step-constant antenna. 
Table 1. Design parameters of step-constant tapered slot antenna (STSA).

\begin{tabular}{cccc}
\hline Parameters & Dimension $(\mathrm{mm})$ & Parameters & Dimension $(\mathrm{mm})$ \\
\hline $\begin{array}{c}\text { Low frequency } \\
(\mathrm{GHz})\end{array}$ & 3.1 & Strip length $(\mathrm{S})$ & 7.0 \\
$\begin{array}{c}\text { High frequency } \\
(\mathrm{GHz})\end{array}$ & 10.6 & Back wall offset length & 10 \\
Step length $\left(\mathrm{S}_{\mathrm{L}}\right)$ & 8.0 & Back wall offset width & 0.4 \\
Step width $\left(\mathrm{S}_{\mathrm{W}}\right)$ & 3.9 & Strip width $\left(\mathrm{S}_{\mathrm{W}}\right)$ & 0.4 \\
Total length $(\mathrm{L})$ & 70.5 & Slot line width $\left(\mathrm{W}_{\mathrm{S}}\right)$ & 0.4113 \\
Total width $(\mathrm{W})$ & 58.7 & Slot line length $\left(\mathrm{L}_{\mathrm{S}}\right)$ & 5.5 \\
Taper length $\left(\mathrm{L}_{\mathrm{T}}\right)$ & 60.0 & Circle radius $(\mathrm{r})$ & 2.5 \\
Taper width $\left(\mathrm{W}_{\mathrm{T}}\right)$ & 58.7 & Substrate thickness $(\mathrm{h})$ & 1.5 \\
\hline
\end{tabular}

\section{Simulation Results and Discussion}

\subsection{Reflection Coefficient}

Reflection coefficient signifies the amount of power reflection from the antenna. The most common parameter of antennas is S11. The amount of power reflection from the antenna represents S11, and it is called reflection coefficient [23] [24]. Another well-known name of the reflection coefficient is return loss. The optimum simulation results are shown in Figures 2-5. In addition, the acceptable limit of reflection coefficient is less than or equal to $-10 \mathrm{~dB}$ [25]. Figure 2 represents the simulated reflection coefficient versus frequency for the different step constant antenna.

From Figure 2, it is clear that the reflection coefficient of STSA is increasing to a specific step size ranging 5 steps to 15 steps and after that, if we increase the step size ranging 15 steps to 30 steps, the reflection coefficient of STSA is again decreasing. This is because for ultra wide band application, users need a high gain antenna, which is confirms in-between 15 to 30 step sizes.

\subsection{Directivity and Gain}

The amount of power transmission in the way of peak radiation defines the antenna gain. Antenna gain relates to the power delivered to the antenna and antenna directivity relates to the power radiated by the antenna. Figure 3(a) and Figure 3(b) represent the simulated gain and directivity for 15 Step-size of the proposed STSA.

\subsection{Voltage Standing Wave Ratio (VSWR)}

The function of the reflection coefficient is VSWR. It defines the reflection of power from the antenna. For antennas, the VSWR must be a real and positive number. When the VSWR is low, the antenna is better matched to the transmission line and the large amount of power is supplied to the antenna. The lowest value of VSWR is 1.0. If $\Gamma$ denotes the reflection coefficient, then the VSWR is defined by the subsequent formula [23] [24]: 


$$
\operatorname{VSWR}=\frac{1+|\Gamma|}{1-|\Gamma|}
$$

Figure 4 shows the VSWR respectively for different step size of the proposed STSAs. Here, minimum VSWR which is equals to 1.00 has been achievable at the operating frequency $5.92 \mathrm{GHz}$.

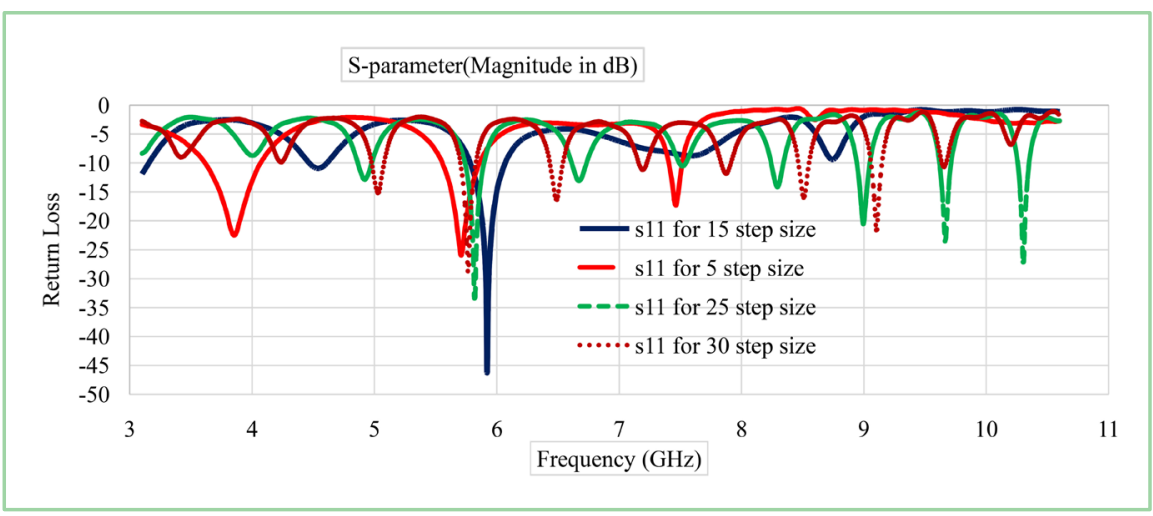

Figure 2. Simulated reflection coefficient for different STSA.

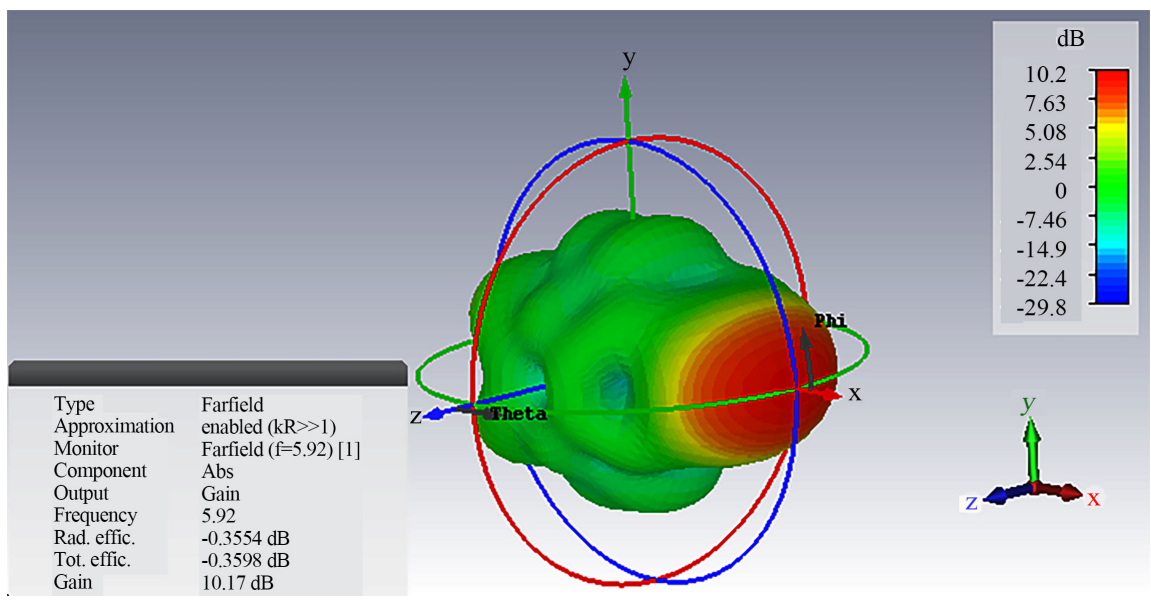

(a)
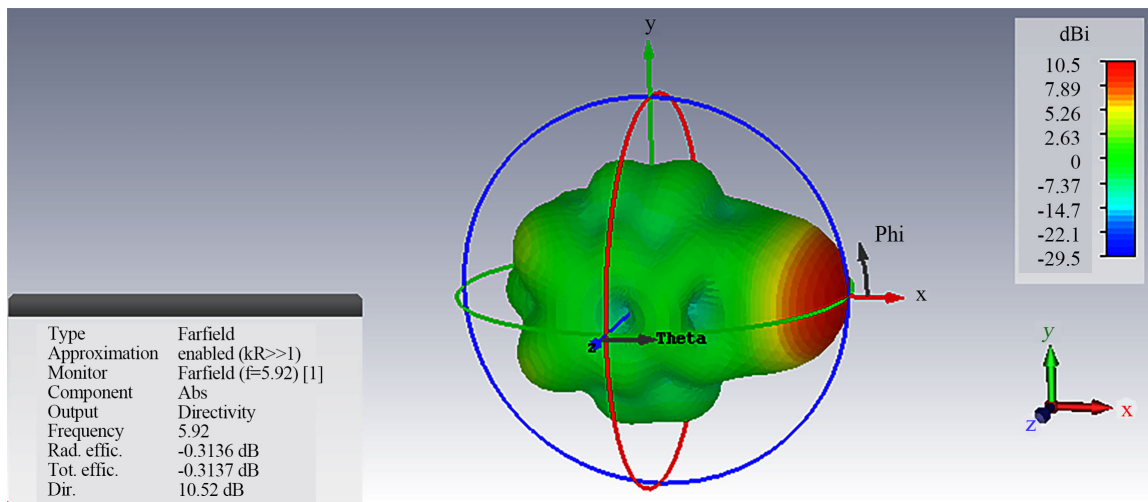

(b)

Figure 3. Simulated (a) gain and (b) directivity for 15 step of the proposed constant tapered slot antenna. 


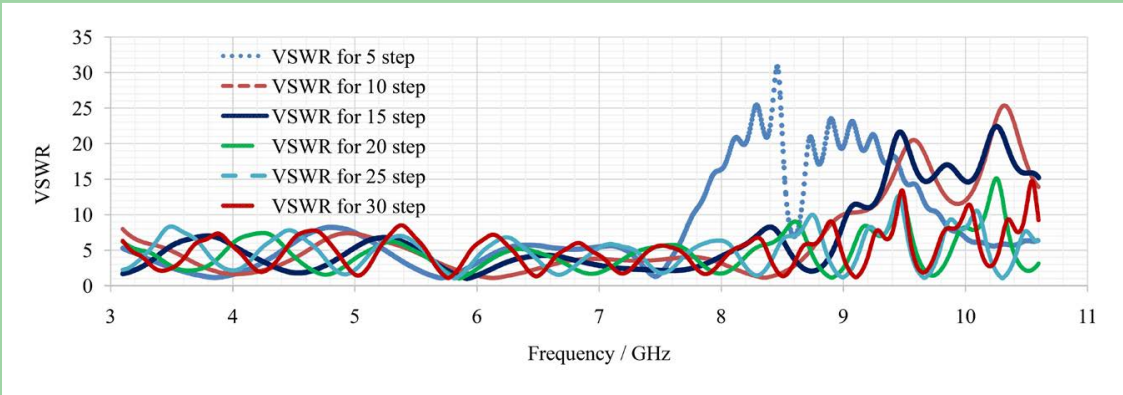

Figure 4. Simulated VSWR for different step-constant tapered slot antenna.

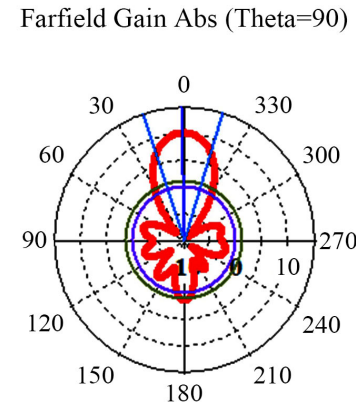

Phi/Degree vs. dB farfield ( $\mathrm{f}=5.92)[1]$

\footnotetext{
Frequency $=5.92$
}

Main lobe magnitude $=10.2 \mathrm{~dB}$

Main lobe direction $=1.0 \mathrm{deg}$.

Angular width $(3 \mathrm{~dB})=35.5 \mathrm{deg}$.

Side lobe level $=-8.9 \mathrm{~dB}$

(a) Gain

Farfield E-Field(r=1m) Abs (Theta $=90)$

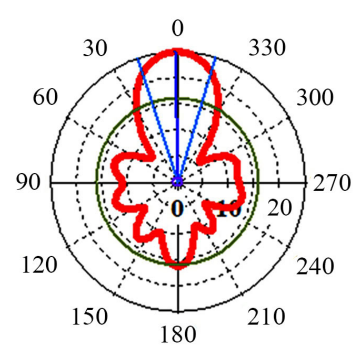

Phi/Degree vs. dBV/m
Frequency $=5.92$

Main lobe magnitude $=24.9 \mathrm{dBV} / \mathrm{m}$

Main lobe direction $=1.0 \mathrm{deg}$.

Angular width $(3 \mathrm{~dB})=35.5 \mathrm{deg}$.

Side lobe level $=-8.9 \mathrm{~dB}$

(b) E-field

Farfield H-Field(r=1m) Abs (Theta=90)

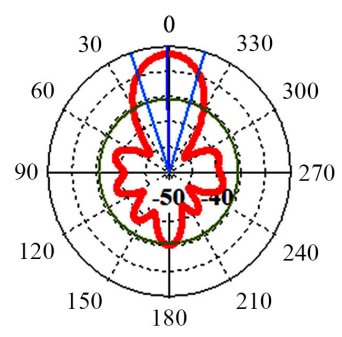

Phi/Degree vs. dBV/m farfield (f=5.92) [1]
Frequency $=5.92$

Main lobe magnitude $=-26.6 \mathrm{dBA} / \mathrm{m}$

Main lobe direction $=1.0 \mathrm{deg}$.

Angular width $(3 \mathrm{~dB})=35.5 \mathrm{deg}$.

Side lobe level $=-8.9 \mathrm{~dB}$

(c) H-field

Figure 5. Simulated polar plot (a) gain, (b) E-field and (c) $\mathrm{H}$-field of proposed step constant antenna. 
After analyzing Figure 4, it is established that at 15 step-size STSA provides best reflection coefficient, gain, directivity and VSWR from other ultra wide-band antennas. In Addition, Table 2 summarizes the simulated results. From Table 2, it can be realized that at 15 steps, the STSA has the optimum reflection coefficient, voltage standing wave ratio, gain, and directivity among others.

\subsection{Radiation Pattern}

The variation of the power radiated by an antenna as a function of the direction away from the antenna defines the radiation pattern. This power variation as a function of the arrival angle is observed in the antennas far field. The region far from the antenna is called far field. In this area, the radiation pattern does not change shape with distance. In addition, this region is dominated by radiated fields, with the E- and $\mathrm{H}$-fields orthogonal to each other and the direction of propagation as with plane waves [23] [24].

Figure 5 represents the simulated polar plot for 15 steps constant antenna at the working frequency of $5.92 \mathrm{GHz}$. The performance of proposed STSA has been analyzed comparing with the performances of other present UWB antennas and tabulated in Table 3 . It is being observed from Table 3 that the STSA designed in this work, has provided the greater outcomes as compared to other UWB antennas reported in the literature [16] [21] [25] [26].

\subsection{Substrate Choice}

A dielectric substrate is an insulator which is a main constituent of the antenna structure. The simulation results of the proposed antenna depend on the material and thickness of the substrate. Substrate thickness has a key role in antenna performance characteristics [24]. The step-constant tapered slot antenna is considered with the material of the substrate and compared with thickness for improve return loss and gain. The obtained results have been tabulated in Table 4 for frequency range $3.1 \mathrm{GHz}$ to $10.6 \mathrm{GHz}$.

From the simulation results in Table 4, it is concluded that the material and thickness of the substrate is the most important part, while designing the slot antenna, especially for step-constant tapered slot type antenna. It is observed that, $1.5 \mathrm{~mm}$ thick substrate is more directive as compared to $1 \mathrm{~mm}$ and $2 \mathrm{~mm}$ thick substrate, in terms of return loss, VSWR, antenna gain and directivity.

Table 2. Performance of the designed STSA.

\begin{tabular}{ccccc}
\hline Antenna step size & Reflection coefficient $(\mathrm{dB})$ & VSWR & Directivity $(\mathrm{dBi})$ & Gain $(\mathrm{dB})$ \\
\hline 5 step & -25.92 & 1.10 & 8.38 & 8.1 \\
10 step & -28.66 & 1.07 & 8.71 & 8.47 \\
15 step & -46.22 & 1.00 & 10.52 & 10.21 \\
20 step & -35.82 & 1.03 & 10.55 & 10.2 \\
25 step & -33.34 & 1.04 & 10.43 & 10.03 \\
30 step & -28.67 & 1.07 & 10.18 & 9.78 \\
\hline
\end{tabular}


Table 3. Performance comparison of the designed step-constant tapered slot antenna (STSA) with other UWB antennas.

\begin{tabular}{cccccc}
\hline \multirow{2}{*}{$\begin{array}{c}\text { Performance } \\
\text { parameter }\end{array}$} & $\begin{array}{c}\text { Proposed } \\
\text { antenna } \\
(15 \text { step size })\end{array}$ & Conventional antennas & \multicolumn{2}{c}{ Graphene based antennas } \\
\cline { 3 - 6 } & -46.22 & -32.5 & -45 & -25.23 & -39.92 \\
\hline $\begin{array}{c}\text { Return } \\
\text { loss (dB) }\end{array}$ & 1.00 & 1.06 & 1.00 & $\mathrm{NR}$ & $\mathrm{NR}$ \\
VSWR & 10.21 & 5.4 & 8.6 & 4.83 & $\mathrm{NR}$ \\
Gain (dB) & 10.52 & $\mathrm{NR}$ & $\mathrm{NR}$ & $\mathrm{NR}$ & $\mathrm{NR}$ \\
$\begin{array}{c}\text { Directivity } \\
(\mathrm{dBi})\end{array}$ & & & & & \\
\hline
\end{tabular}

${ }^{*} \mathrm{NR}=$ Not Reported.

Table 4. Comparison analysis of varying thicknesses and substrate.

\begin{tabular}{ccccccc}
\hline & \multicolumn{3}{c}{ Substrate Thickness $(\mathrm{mm})$} & \multicolumn{3}{c}{ Substrate } \\
\cline { 2 - 7 } Simulation Results & 1.5 & 2.0 & 1.0 & $\begin{array}{c}\text { Taconic } \\
\text { RF-60A }\end{array}$ & $\begin{array}{c}\text { Roger } \\
\text { RO3006 }\end{array}$ & FR-4 \\
\hline Return Loss & -46.22 & -32 & -21 & -43 & -46.22 & -20.46 \\
VSWR & 1.00 & 1.05 & 1.19 & 1.01 & 1.00 & 1.20 \\
Gain & 10.21 & 8.23 & 10.2 & 10.2 & 10.21 & 9.95 \\
Directivity & 10.52 & 8.9 & 10.5 & 10.52 & 10.52 & 11.7 \\
\hline
\end{tabular}

\section{Conclusion}

In this paper the simulation results show that gain and refection co-efficient of proposed step-constant TSA for different step size is increasing to a specific step size (5-step to 15-step) and after that if we increase the step size (15-step to 30-step) the gain and refection co-efficient of STSA is decreasing. An STSA is designed on a Rogers (RO3006) substrate. Back wall offset is the extra metallization fixed at the opening of the slot line. An increase or decrease in the back wall offset parameter results in rapid changes in the return loss characteristics of the antenna. But the above condition is true only for certain values of back wall offset parameter.

\section{Conflicts of Interest}

The authors declare no conflicts of interest regarding the publication of this paper.

\section{References}

[1] Charoensiri, Y., Thaiwiro, W. and Akkaraekthalin, P. (2017) Design of U1tra-Wideband Tapered Slot Antenna by Using Binomial Impedance Transformer. IEEE Conference on Antenna Measurements \& Applications, 71, 251-260. https://doi.org/10.1515/freq-2016-0131

[2] Hossain, M., et al. (2019) Numerical Analysis and Design of Photonic Crystal Fiber Based Surface Plasmon Resonance Biosensor. Journal of Sensor Technology, 9, 27-34. https://doi.org/10.4236/jst.2019.92003 
[3] Sakib, N., Hossain, B., Al-Tabatabaie, K.F., Mehedi, I.M., Hasan, T., Hossain, A. and Amiri, I.S. (2019) High Performance Dual Core D-Shape PCF-SPR Sensor Modeling Employing Gold Coat. Results in Physics, 15, Article ID: 102788. https://doi.org/10.1016/j.rinp.2019.102788

[4] Biplob, H., Mehedi, I.M., Moznuzzaman, M., Abdulrazak, L.F. and Hossain, A. (2019) High Performance Refractive Index SPR Sensor Modeling Employing Graphene Tri Sheets. Results in Physics, 15, Article ID: 102719. https://doi.org/10.1016/j.rinp.2019.102719

[5] Shushama, K.N., Rana, M.M., Inum, R. and Hossain, M.B. (2017) Graphene Coated Fiber Optic Surface Plasmon Resonance Biosensor for the DNA Hybridization Detection: Simulation Analysis. Optics Communications, 383, 186-190. https://doi.org/10.1016/j.optcom.2016.09.015

[6] Hossain, M.B. and Rana, M. (2016) Graphene Coated High Sensitive Surface Plasmon Resonance Biosensor for Sensing DNA Hybridization. Sensor Letters, 14, 145-152. https://doi.org/10.1166/sl.2016.3596

[7] Hossain, M.B. and Rana, M.M. (2016) DNA Hybridization Detection Based on Resonance Frequency Readout in Graphene on Au SPR Biosensor. Journal of Sensors, 2016, Article ID: 6070742. https://doi.org/10.1155/2016/6070742

[8] Hossain, B., Khan, M.M.R., Rahman, S., Badrudduza, S.S.B., Sabiha, M.M. and Rana, M. (2019) Graphene- $\mathrm{MoS}_{2}-\mathrm{Au}-\mathrm{TiO}_{2}-\mathrm{SiO}_{2}$ Hybrid SPR Biosensor: A New Window for Formalin Detection. Journal of Materials and Applications, 8, 51-58. https://doi.org/10.32732/jma.2019.8.2.51

[9] Hossain, M.B., Rana, M.M., Abdulrazak, L.F., Mitra, S. and Rahman, M. (2019) Design and Analysis of Graphene- $\mathrm{MoS}_{2}$ Hybrid Layer Based SPR Biosensor with $\mathrm{TiO}_{2}-\mathrm{SiO}_{2}$ Nano Film for Formalin Detection: Numerical Approach. Optical and Quantum Electronics, 51, 195-207. https://doi.org/10.1007/s11082-019-1911-Z

[10] Hossain, M.B., Rana, M.M., Abdulrazak, L.F. and Mitra, S. (2019) Graphene-MoS with $\mathrm{TiO}_{2}-\mathrm{SiO}_{2}$ Layers Based Surface Plasmon Resonance Biosensor: Numerical Development for Formalin Detection. Biochemistry and Biophysics Reports, 18, Article ID: 100639. https://doi.org/10.1016/j.bbrep.2019.100639

[11] Hossain, M.B., Akib, T.B.A., Abdulrazak, L.F. and Rana, M. (2019) Numerical Modeling of Graphene-Coated Fiber Optic Surface Plasmon Resonance Biosensor for BRCA 1 and BRCA 2 Genetic Breast Cancer Detection. Optical Engineering, 58, Article ID: 037104. https://doi.org/10.1117/1.OE.58.3.037104

[12] Islam, M.M., Islam, M., Shimul, Y.C., Rahman, A., Ruhe, A.A., Hassan, M., et al. (2019) FDTD Analysis Fiber Optic SPR Biosensor for DNA Hybridization: A Numerical Demonstration with Graphene. Journal of Materials and Applications, 8, 13-19. https://doi.org/10.32732/jma.2019.8.1.13

[13] Hossain, M.B., Islam, M., Abdulrazak, L.F., Rana, M.M., Akib, T.B.A. and Hassan, M. (2019) Graphene-Coated Optical Fiber SPR Biosensor for BRCA1 and BRCA2 Breast Cancer Biomarker Detection: A Numerical Design-Based Analysis. Photonic Sensors, 9, 1-13. https://doi.org/10.1007/s13320-019-0556-7

[14] Hossain, M.B., Hassan, M., Abdulrazak, L.F., Rana, M.M., Islam, M.M. and Rahman, M.S. (2019) Graphene- $\mathrm{MoS}_{2}-\mathrm{Au}-\mathrm{TiO}_{2}-\mathrm{SiO}_{2}$ Hybrid SPR Biosensor for Formalin Detection: Numerical Analysis and Development. Advanced Materials Letters, 10, 656-662. https://doi.org/10.5185/amlett.2019.0001

[15] Hossain, B., Tasnim, T., Abdulrazak, L.F., Rana, M. and Islam, R. (2019) A Numerical Approach to Design the Kretschmann Configuration Based Refractive Index Graphene- $\mathrm{MoS}_{2}$ Hybrid Layers with $\mathrm{TiO}_{2}-\mathrm{SiO}_{2}$ Nano for Formalin Detection. Photonic Sensors, 1-13. https://doi.org/10.1007/s13320-019-0566-5 
[16] Inum, R., Rana, M.M. and Shushama, K.N. (2017) Development of Graphene Based Tapered Slot Antennas for Ultra-Wideband Applications. Progress in Electromagnetics Research C, 79, 241-255. https://doi.org/10.2528/PIERC17072611

[17] The Federal Communications Commission (2007) Revision of Part 15 of the Commission's Rules Regarding Ultra Wideband Transmission Systems. First Report and Order, FCC 03-33, Washington DC.

[18] Lee, D.-H., Yang, H.-Y. and Cho, Y.-K. (2012) Tapered Slot Antenna with Band Notched Function for Ultra-Wideband Radios. IEEE Antennas and Wireless Propagation Letters, 11, 682-685. https://doi.org/10.1109/LAWP.2012.2204718

[19] Beada, J., Amin, M. and David, I. (2014) Microwave System for Head Imaging. IEEE Transactions on Instrumentation and Measurement, 63, 117-123. https://doi.org/10.1109/TIM.2013.2277562

[20] Yin, X., Su, Z., Hong, W. and Cui, T.J. (2005) An Ultra-Wideband Tapered Slot Antenna. 2005 IEEE Antennas and Propagation Society International Symposium, Washington DC, 3-8 July 2005, 516-519.

[21] Gibson, P.J. (1979) The Vivaldi Aerial. 1979 9th European Microwave Conference, Brighton, 17-20 September 1979, 101-105.

https://doi.org/10.1109/EUMA.1979.332681

[22] Nand Mahapatra, P.S. (1979) A Novel MIC Slot-Line Antenna. 1979 9th European Microwave Conference, Brighton, 17-20 September 1979, 120-124.

[23] Unadkat, V., Dwivedi, V.V., Jani, R. and Thanki, R. (2013) Design of Corrugated Linearly Tapered Slot Antenna for Wireless Apps. LAP Lambert Academic Publishing, Mauritius, 104.

[24] Asif, S.M., Iftikhar, A., Braaten, B.D. and Khan, M.S. (2016) Design of an Ultra-Wideband Antenna Using Flexible Graphene-Based Conductor Sheets. IEEE International Symposium on Antennas and Propagation, Fajardo, Puerto Rico, 26 June-1 July 2016, 1863-1864. https://doi.org/10.1109/APS.2016.7696638

[25] Vignesh, N., Kumar, G.A.S. and Brindha, R. (2014) Design and Development of a Tapered Slot Vivaldi Antenna for Ultra-Wide Band Application. International Journal of Advanced Research in Computer Science and Software Engineering, 4, 174-178.

[26] Azim, R., Islam, M.T. and Misran, N. (2011) Compact Tapered-Shape Slot Antenna for UWB Applications. IEEE Antennas and Wireless Propagation Letters, 10, 1190-1193. https://doi.org/10.1109/LAWP.2011.2172181

[27] Jiang, Y., Yuan, R., Gao, X., Wang, J., Li, S. and Lin, Y. (2016) An Ultra-Wideband Pattern Reconfigurable Antenna Based on Graphene Coating. Chinese Physics B, 25, 1-7. https://doi.org/10.1088/1674-1056/25/11/118402 